\title{
Study of Microleakage between Material Restoration Glass Ionomer Cement and Alkasite in Class V Cavity (G.V. Black)
}

\author{
Iin Sundari1,*, Diana Setya Ningsih ${ }^{2}$, Raudhatul Jannah ${ }^{3}$ \\ ${ }^{1}$ Department of Dental Material, Faculty of Dentistry, Universitas Syiah Kuala, Banda Aceh, 23111, Indonesia \\ ${ }^{2}$ Department of Dental Material, Faculty of Dentistry, Universitas Syiah Kuala, Banda Aceh, 23111, Indonesia \\ ${ }^{3}$ Undergraduate Student of Faculty of Dentistry, Universitas Syiah Kuala, Banda Aceh, 23111, Indonesia \\ *Corresponding Author email: rh_iin@unsyiah.ac.id
}

\begin{abstract}
Microleakage is a gap between the surface of the tooth and the restoration caused by the failure of the restoration. Glass Ionomer Cement (GIC) and Alkasite are materials with good clinical appearance, but the mechanical strength of GIC was lower than Alkasite and the microleakage occurs in both restorations. Purpose: This study aims to determine the microleakage between GIC and Alkasite restorations in the Class V cavity for 1 day, 7 days, and 30 days after restoration in the tooth. Materials and methods: This study used 30 maxillary premolars and was divided into six groups. Group A restored by GIC and group B by Alkasite. Groups A1 and B1 were restored and incubated for 1 day, groups A2 and $\mathrm{B} 2$ for 7 days, groups $\mathrm{A} 3$ and $\mathrm{B} 3$ for 30 days. All specimens were incubated at $37^{\circ} \mathrm{C}$ and isolated with nail varnish except for the restored areas before immersion with $1 \%$ methylene blue at room temperature for 1 day. The specimens were cleaned and cut longitudinally, then observed by a stereomicroscope and scored 0-4. Results: Average values of GIC and Alkasite microleakage after 1 day were greater than 7 days and 30 days. a Comparison of the average microleakage values of GIC and Alkasite shows microleakage values of GIC are greater than Alkasite. However, statistical analysis test results showed that there were no significant microleakage values between GIC and Alkasite after 1 day, 7 days, and 30 days $(p>0.05)$.
\end{abstract}

Keywords: microleakage, glass ionomer, alkasite, class $V$

\section{INTRODUCTION}

In the $19^{\text {th }}$, century Glass Ionomer Cement (GIC) was used by dentistry [1]. Development of this material was important to reach a good adhesion of restoration material and tooth structure to minimalized microleakage [2]. Microleakage caused discoloration around margin restoration, sensitivity after treatment, secondary caries, failure of restoration, pulp pathology, and removable restoration [3].

Samanta et al's research showed the Mean of microleakage GIC on class $\mathrm{V}$ cavity in $1.5 \mathrm{~mm}$ depth around 1.280 [4]. The GIC contains filler such as fluoro aluminosilicate glass and matrix as polymer or copolymer from carbolic acid. GIC is water-based and self-adhesive material. This material is used for cervical caries restoration, but the weak point of GIC are solubility and low mechanical strength for the initial setting [4,5]. To improve the quality of restoration material, a resin material used for new restoration that has the same color with the tooth and released fluor, and has a better mechanical strength than GIC, named "Alkasite" $[3,6,7]$.

Alkasite is formed by powder and liquid then manually manipulated. Alkasite contains organic monomer in the liquid from Urethanedimethacrylate (UDMA), Tricyclodecane Dimethanol Dimethacrylate (DCP), Tetramethyl xylene diurethane dimethacrylate (aromatic aliphatic-UDMA), and polyethylene glycol 400 dimethacrylate (PEG-400 DMA) which made a crosslinked polymerization so that improved the mechanical strength of alkasite. In 2014 alkasite was tested on a mouse and since 2015 microleakage on alkasite was tested [1]. The alkasite is used for a cavity in class I, class II and class V restoratioN [6,8]. Samanta et al's research about alkasite on class $\mathrm{V}$ cavity showed microleakage Mean was 0,28 [4].

Most of the researchers tested the difference of microleakage Mean on GIC and alkasite. George and Bhandary's research on class II cavity after 24 hours showed that microleakage on GIC (3.00) was higher than 
alkasite (0.30) [3]. Sundari et al's research that tested microleakage of GIC as a cover of fissure after 30 days showed Mean microleakage of GIC was 1.875 and another research from Sahu et al on class I cavity after 48 hours showed the improvement of microleakage Mean in alkasite $(0.99868)$ [9, 10].

Based on the research above, there is a difference in microleakage Mean from both materials. The change in ionic bond happened for the first week after restoration and improved the bond strength of GIC after 30 days and decrease the Mean on microleakage [11]. Aklasite still had the change of flexural strength after 7 days until 30 days after restoration [1]. Therefore, this research is interested to study the difference of microleakage between GIIC and alkasite for restoration material on class V cavity-based G.V, Black classification in 1 day, 7 days, and 30 days.

\section{RESEARCH METHODS}

This research is an experimental laboratory design with a postest only method to measure microleakage Mean on GIC and alkasite for class V cavity on premolar tooth.

The specimen in this research was a maxillary premolar tooth with no caries, no fracture, and no restoration. Then the tooth was prepared with class V cavity on buccal for $4 \mathrm{~mm}$ mesial-distal, $2 \mathrm{~mm}$ occlusogingival, and $2 \mathrm{~mm}$ buccolingual as seen in Figure 1[12].

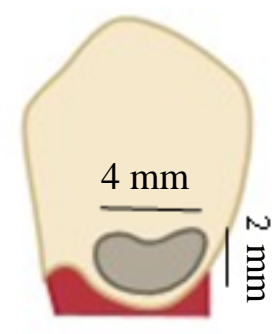

Figure 1. Preparation class V cavity on premolar tooth

They were divided into 6 groups with 5 specimens for each group. Group A for GIC and group B for alkasite. Group A1 GIC soaked in aqua dest for 1 day, group A2 GIC soaked in aqua dest for 7 days and group A3 GIC soaked in aqua dest for 30 days. For group B1 alkasite was soaked in aqua dest in 1 day, B2 for 7 days, and B3 for 30 days

Premolar tooth from dentist clinic was rinsed and soaked in water. The tooth will be prepared with micromotor and round bur, cylindrical bur, and inverted bur. Round bur used for the depth of the cavity, inverted bur for expand and make bevel on cavity for alkasite restoration. The tooth was prepared with class $\mathrm{V}$ cavity on buccal for $4 \mathrm{~mm}$ mesial-distal, $2 \mathrm{~mm}$ occlusogingival, and $2 \mathrm{~mm}$ buccolingual $[12,13]$.
Specimen group A was applied with $10 \%$ polyacrylic acid as a dentin conditioner with a micro applicator in 20 seconds. Then, the specimen was rinsed with a syringe and dry it but not too dry [13].

The ratio of powder and liquid of GIC was 1:1 then mixed in 30 seconds until it got putty consistency. The GIC was put into the cavity of the tooth with a plastic filling instrument $[13,14]$.

The specimen group B will be applied to adhesive material before being restored with alkasite. Adhesive material applied with a micro brush then thinned with chip blower then light curing for 10 seconds. After that, alkasite was manipulated powder liquid for 1:1. The powder mixed slowly until the powder and liquid homogenated for 5 to 60 seconds. Then alkasite was put into the cavity of the tooth and set after 4 minutes $[1,8]$.

The restoration of the specimen with GIC and alkasite was restored in the incubator with a temperature of $37^{\circ} \mathrm{C}$ to make a similar environment with our mouth for 1 day (specimen A1 and B1), 7 days (specimen A2 and B2), and 30 days (specimen A3 and B3). After that, the specimen was covered with a nail varnish except in $2 \mathrm{~mm}$ around the restoration area. After the nail varnish dried, each specimen was soaked in $1 \%$ methylene blue liquid for 1 day. After the immersion specimen was rinsed for 1 minute underwater flow. Then the specimen was cut along the longitudinal midline of restoration with a carborundum disc [12].

The measurement of microleakage to observed dye penetration is used the scoring technique with the criteria

a. Score 0 : no color penetration

b. Score 1 : color penetration along enamel wall to dentino-enamel junction

c. Score 2 : color penetration along cavity wall passed dentino-enamel junction up to $1 / 2$ cavity depth

d. Score 3 : color penetration distributed along the cavity wall without including the axial wall

e. Score 4 : color penetration distributed along the axial wall [15].

The specimen was observed with 20 times magnification in a stereomicroscope [12]. The comparison of microleakage between this material (GIC with Alkasite) was analyzed by Mann Whitney analysis. The comparison of microleakage between GIC and Alkasite was analyzed by Kruskal Wallis tested.

\section{RESULTS}

The measurement of microleakage in this research used a scoring technique with a score of 0-4. Observation result for microleakage of GIC and alkasite on class $\mathrm{V}$ cavity after 1 day, 7 days and 30 days testing showed in Table 1. This table approved that all tested the specimen on GIC with 1 day (A1) and 7 days (A2) tested had microleakage with a score 
1 to 2. Meanwhile, GIC specimen for 30 days (A3) testing only has 1 specimen with no microleakage on that specimen. This is contra with alkasite specimen that microleakage only happened in specimen with 1 day (B1) testing, and for specimen with 7 days (B2) and 30 days (B3) testing, there is no microleakage happened. There is an improvement of specimen number that no microleakage on the specimen with 30 days testing was 3 specimen.
The biggest percentage value of microleakage on the GIC specimen happened in 1 day (A1), 7 days (A2), and alkasite in 1 day (B1) duration of treatment about $100 \%$. Percentage of GIC with 30 days (A3) soaked smaller than GIC in 1 day (A1), 7 days (A2), and alkasite in 1 day (B1) with $80 \%$. Alkasite specimen with 7 days (B2) duration showed that $60 \%$ but in 30 days (B3) showed microleakage percentage with a small number around $40 \%$.

Table 1. Percentage microleakage in 6 group specimen

\begin{tabular}{|c|c|c|c|c|c|c|c|c|}
\hline \multirow{2}{*}{\multicolumn{2}{|c|}{ Group }} & \multirow{3}{*}{$\begin{array}{r}\text { Duration } \\
1 \text { day }\end{array}$} & \multicolumn{3}{|c|}{$\begin{array}{l}\text { Microleakage } \\
\text { Score }\end{array}$} & \multirow{3}{*}{$\begin{array}{l}\text { n } \\
5\end{array}$} & \multirow{3}{*}{$\begin{array}{c}\begin{array}{c}\text { Microleakage } \\
\text { Percentage (\%) }\end{array} \\
100 \%\end{array}$} & \multirow{3}{*}{$\begin{array}{c}\text { Score Modus } \\
1\end{array}$} \\
\hline & & & 0 & 1 & 2 & & & \\
\hline \multirow{3}{*}{ GIC } & A1 & & - & 3 & 2 & & & \\
\hline & A2 & 7 days & - & 4 & 1 & 5 & $100 \%$ & 1 \\
\hline & A3 & 30 days & 1 & 3 & 1 & 5 & $80 \%$ & 1 \\
\hline \multirow{3}{*}{ Alkasite } & B1 & 1 day & - & 4 & 1 & 5 & $100 \%$ & 1 \\
\hline & B2 & 7 days & 2 & 3 & - & 5 & $60 \%$ & 1 \\
\hline & B3 & 30 days & 3 & 2 & - & 5 & $40 \%$ & 0 \\
\hline
\end{tabular}

Score Modus of microleakage in table 1 showed there is no difference with the specimen group of GIC with score 1. But there is a difference of Modus score in alkasite specimen for 30 days (B3) that showed Modus score 0 from another alkasite group.

\subsection{Comparison of Microleakage of GIC and Alkasite Based on Duration Treatment}

Microleakage was tested with Kruskal Wallis to find out the comparison of microleakage between GIC and Alkasite based on duration treatment.

Table 2. Significant Value of GIC microleakage

\begin{tabular}{|c|c|c|l|c|}
\hline Group & Duration & $\mathbf{n}$ & $\begin{array}{c}\text { Mean of } \\
\text { Microleakage }\end{array}$ & \multirow{2}{*}{$\boldsymbol{p}$} \\
\cline { 1 - 4 } A1 & 1 day & 5 & $1.40 \pm 0.548$ & \multirow{2}{*}{0.565} \\
\cline { 1 - 3 } A2 & 7 days & 5 & $1.20 \pm 0.447$ & \\
\hline A3 & 30 days & 5 & $1.00 \pm 0.707$ & \\
\hline
\end{tabular}

* Signicant value from Kruskal Wallis statistic $(p<0.05)$

Table 2 showed microleakage mean of GIC specimen in 1 day had the biggest microleakage than 7 days or 30 days. The statistical data showed that there is no significant difference from the Mean of microleakage in GIC restoration based on duration treatment for 1 day, 7 days, and 30 days.

The biggest mean of microleakage alkasite for 1 day, meanwhile for 7 days and 30 days decreased. But there is no significant difference happened in alkasite with 1 day, 7 days, and 30 days duration of treatment with $p>0.05$ (Table 3 ).
Table 3. Significant Values of Alkasite Microleakage

\begin{tabular}{|c|c|c|c|c|}
\hline Group & Duration & $\mathbf{n}$ & $\begin{array}{c}\text { Mean of } \\
\text { Microleakage }\end{array}$ & \multirow{2}{*}{$\boldsymbol{p}$} \\
\cline { 1 - 4 } B1 & 1 day & 5 & $1.20 \pm 0.447$ & \multirow{2}{*}{0.090} \\
\cline { 1 - 3 } B2 & 7 days & 5 & $0.60 \pm 0.548$ & \\
\hline B3 & 30 days & 5 & $0.40 \pm 0.548$ & \\
\hline
\end{tabular}

* Signicant value from Kruskal Wallis statistic $(p<0.05)$

\subsection{Comparison of Microleakage of GIC and Alkasite Based on Time Duration}

Table 4 showed that the average score of microleakage that occurs in GIC restoration materials was treated for 1 day was higher than the average value of microleakage scores that occur in Alkasite which was treated for 1 day, $1.40 \pm 0.548$ and $1.20 \pm 0.447$ each. The mean score of microleakage that occurred in GIC restoration materials was treated for 7 days was also higher than Alkasite which was treated for 7 days, $1.20 \pm 0.447$ and $0.60 \pm 0.548$ each. In GIC restoration materials that were treated for 30 days, the average microleakage score was $1.00 \pm 0.707$ and in Alkasite $0.40 \pm 0.548$. This also shows that the average value of microleakage that occurs in GIC is higher than Alkasite. However, based on the results of statistical tests, there was no significant difference in the mean value of microleakage between the groups of GIC and Alkasite based on the duration of 1 day, 7 days, and 30 days. 
Table 4. The average score of GIC microleakage

\begin{tabular}{|c|c|c|c|c|}
\hline Group & Duration & $\mathbf{n}$ & $\begin{array}{c}\text { Average score of microleakage } \\
\text { Average score } \pm \text { SD }\end{array}$ & $p$ \\
\hline A1 (GIC) & \multirow{2}{*}{1 day } & 5 & $1.40 \pm 0.548$ & \multirow{2}{*}{0.513} \\
\hline B1 (Alkasite) & & 5 & $1.20 \pm 0.447$ & \\
\hline A2 (GIC) & \multirow{2}{*}{7 days } & 5 & $1.20 \pm 0.447$ & \multirow{2}{*}{0.093} \\
\hline B2 (Alkasite) & & 5 & $0.60 \pm 0.548$ & \\
\hline A3 (GIC) & \multirow{2}{*}{30 days } & 5 & $1.00 \pm 0.707$ & \multirow{2}{*}{0.166} \\
\hline B3 (Alkasite) & & 5 & $0.40 \pm 0.548$ & \\
\hline
\end{tabular}

* Signicant value from Mann Whitney statistic $(p<0.05)$

\section{DISCUSSION}

Microleakage is a gap between the surface of the tooth and the restoration caused by bacterial penetration, molecules, and oral liquid [16]. This research showed that microleakage between GIC and Alkasite based on score Modus, the percentage and Mean decreased from 1 day, 7 days until 30 days (Table 1). All GIC specimens tested in 1 day (A1) and 7 days (A2) had a microleakage. The score was given by the depth of a methylene blue liquid penetration that showed a blue line on marginal restoration and tooth cavity as seen in Figure 2A but in Figrure 2B there is no penetration of a methylene blue liquid on marginal restoration and tooth cavity.

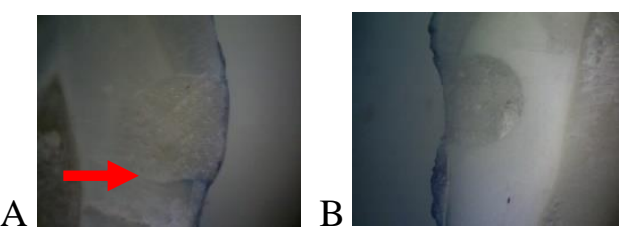

Figure 2. Microleakage figure used stereomicroscope (20 x magnification) A. The specimen showed color penetration $\mathrm{B}$. The specimen showed there is no color penetration

Tables 1 and 2 showed the percentage and Mean of microleakage on GIC and Alkasite for 1 day, 7 days and 30 days was decreased. This is could happen because of the maturation process on GIC. The maturation of GIC for 1 day (A1) and 7 days (A2) has not been completed. The maturation process continued after restoration and caused the delivery of fluor from GIC to the tooth surfaces which contains Hydroxyapatite (HAp). The transfer of the ion formed an ionic adhesion between HAp $\left(\mathrm{Ca}_{10}\left(\mathrm{PO}_{4}\right)_{6}(\mathrm{OH})_{2}\right)$ released $(\mathrm{OH})_{2}$ molecule with fluor [9]. The formation of this ionic bond improved bonding strength between restoration and tooth cavity. However, there is no significant difference in the Modus score of microleakage GIC after 1 day, 7 days, and 30 days. This can be happened because of slow maturation in GIC. Nicholson said that the maturation process of GIC is held from the first day and completed in 4-6 weeks after restoration [11].
The microleakage score in alkasite showed in table 5, which is there is no microleakage in 7 days (B2) or 30 days (B3). This might happened because of the transfer of ions from Alkasite to tooth surface so that formed greater bonding between the tooth structure and restoration after 7 days (B2) and 30 days (B3) if compared with Alkasite on 1 day (B1). This is the same as with Todd's research (in 2016) that showed fluoride ions, calcium and hydroxide improved after the first day of polymerization until the next duration of time. The ions were released to inhibit the remineralization process and improve restoration bonding to the tooth.

The percentages and Modus score of microleakage on Alkasite decreased (table 1). This might happen because of the release of calcium ions that improved all the time. The result of Todd's research showed the minerals such as fluoride calcium, phosphate calcium, and hydroxyapatite were formed after 30 days of restoration than the first day. The percentages and Modus score of microleakage on Alkasite are directly proportional with the Mean of microleakage. However, the statistical results showed there is no significant difference between alkasite based on duration treatment with $p>0.05$ value (Table 3 ). The researcher thought that the release of ions number from Alkasite from the first day until 30 days did not improve [1].

Table 4 showed the Mean microleakage of Alkasite with a 1-day duration smaller than GIC with a 1-day duration. Mean of microleakage of Alkasite with 7 days and 30 days duration also smaller than GIC with 7 and 30 days duration. This result related fluoride calcium and phosphate layer that formed on Alkasite was higher than GIC. Todd also showed the graphic of Alkasite calcium ion released after 30 days with neutral $\mathrm{pH}$ around $10-20 \mu \mathrm{g} / \mathrm{cm}^{2}$, however in GIC only $1-3 \mu \mathrm{g} / \mathrm{cm}^{2}$ [1].

The researcher thought that the small Mean value of microleakage on Alkasite was caused by the value of elasticity modulus of Alkasite that smaller than GIC, with only 10-13 GPa but GIC had 15-21 GPa. This point corresponds with the cross-link between monomer and silane in the content of is filler and alkasite that give the pressure at the cavity while the polymerization material process takes place. The alkasite that has weak modulus elasticity that can 
decrease shrinkage stress thus might assess to minimalize shrinkage force. The minimum shrinkage force is assessed in decreasing the gap made between the restoration and tooth surface thus microleakage that has formed becomes smaller [1,17]. Although the average value of microleakage of GIC is higher than Alkasite, the estimation of the level of microleakage between this material demonstrates that there is no Meaningful difference of the lever of Microleakage after 1 day, 7 days, and 30 days.

The factors that have been contributed at this no significant difference of the level of microleakage between GIC and Alkasite in this study is due to the same featured between this restoration material that released the fluor ion so that the hydroxyapatite turned into fluorapatite process take place and the use of dentin conditioner before applying the GIC so that the bond between GIC and the surface of the tooth not only chemically, but also mechanically. The dentin conditioner consists of polyacrylate acid $10 \%$ that plays a role in washout smear layer, debris, and leaving smear plug at the surface of the dentin. The smear plug is the layer that assesses the adhesion process between GIC and the surface of the cavity thus increasing the GIC bond and decreasing microleakage $[9,18]$. Cocoa butter also has been used in this study. The usage of cocoa butter works for covering the GIC from water contamination during the initial setting process that may be decreasing GIC adhesion to the surface of the tooth [19]. The other factor that has been contributed to this no significant difference in the level of microleakage between GIC and Alkasite in this study is the usage of adhesive material with a one-step self-etch technique before Alkasite restoration.

The alkasite restoration material used is Centurion $\mathrm{N}$-Ivoclar Vivadent with adhesive from Terrific Nbond Universal Vivadent. The usage of the adhesive before applying Alkasite assess in decreasing microleakage. The technique that has been used in this study is one-step self-etch where the application of adhesive with a micro brush in 10 seconds and then make it thinner with weak pressure of air from chip blower before light-curing. This technique does not flush so the accumulation of hydroxyapatite is dissolved to the surface of the cavity [20]. Based on the study of Sundari et al, the one-step self-etch technique shows the level of microleakage is bigger than totaletch [21]. Therefore, there is no significant difference at the average level of microleakage in Alkasite in comparison with the level of microleakage in GIC.

\section{CONCLUSION}

The microleakage value of Alkasite after 1 day, 7 days, and 30 days duration was smaller than GIC restoration after 1 day, 7 days, and 30 days duration. But statistical results showed that there is no significant difference between GIC and Alkasite as a restoration material in class $\mathrm{V}$ cavity.

\section{AUTHORS' CONTRIBUTIONS}

I.S. conceived of the presented idea, I.S., D.S.N., and R.J. contributed to the design and to the writing of the manuscript.

\section{REFERENCES}

[1] Todd J C. "Scientific Documentation: Centurion N; Ivoclar-Vivadent". Press: Schaan, Liechtenstein. 2016;1-58

[2] Sutrisman H, Abidin T. Pengaruh chitosan belangkas ( Tachypleus gigas ) nanopartikel terhadap celah antara berbagai jenis semen ionomer kaca dengan dentin ( The effect of horseshoe crab ( Tachypleus gigas ) dderived nanoparticle chitosan on interface between various glass ionom. Dent J.2014;47(3):5-121

[3] George P, Bhandary S. A Comparative Microleakage Analysis of a Newer Restorative Material-An Exvivo Study. IOSR J Dent Med Sci e-ISSN. 2018;17(12):56-60

[4] Samanta S, Das UK, Mitra A. Comparison of Microleakage In Class V Cavity Restored with Flowable Composite Resin, Glass Ionomer Cement and Centurion N. Imp J Interdiscip Res (IJIR. 2017;3(8):3-180

[5] Sakaguchi RL, Powers JM. Craig's restorative dental materials, 13th edition. Vol. 213, Elsevier. 2012. p. 152-336

[6] Sadananda V, Shetty C, Hegde M, S. Bhat G. Alkasite restorative material: flexural and compressive strength evaluation. Res J Pharm Biol Chem Sci. 2018;9(5):82-2179

[7] Arun Kumar S, Ajitha P. Evaluation of compressive strength between Centurion $\mathrm{N}$ and high copper amalgam - An in vitro study. J Drug Invent Today. 2019;12(2): 7-255

[8] de Jesús Cedillo Valencia J, Manuel Cedillo Felix V, I Afrashtehfar K. Alkasites, a New Alternative to Amalgam. Report of a Clinical Case. Acta Sci Dent Scienecs. 2019;3(10):9-11

[9] Sundari I, Diansari V, Julianti E. Perbandingan Tingkat Kebocoran Mikro Antara Resin Komposit Dan Glass Ionomer Cement Sebagai Bahan Penutupan Fisura (Evaluasi InVitro Setelah Satu Bulan Aplikasi). Cakradonya Dent J. 2018;10(2):8-121

[10] Sahu S, Ali N, Misuriya A, Vijaywargiya P, Saha SG, Bharadwaj A. Comparative Evaluation of Microleakage in Class I Cavities Restored with Amalgam , Bulk-fill Composite and Cention-N - 
An In Vitro Confocal Laser Scanning Microscope Study. INTERN J Curr Res. 2018;6(1):5-81

[11] Nicholson JW. Maturation processes in glassionomer dental cement. Acta Biomater Odontol Scand. 2018;4(1):63-71

[12] Meshram $\quad P \quad V, \quad$ Meshram VS. Comparative Evaluation of Microleakage Around Class V Cavities Restored With New Alkasite Material and Two Difference Flowable Composite Comparative Evaluation of Microleakage Around Class V Cavities Restored With New Alkasite Material and Two Difference Fl. Int J Curr $\quad$ Res. 2018;10(04):1-3

[13] Sundari I, Ningsih DS, Putri CF. Perbandingan Kebocoran Mikro Antara Basis Gic Conventional Dan Rmgicpada Restorasi Resin Komposit Nanofiller Dengan Teknik Sandwich. Cakradonya Dent J. 2013;5(2):542-618

[14]Lestari S. Kekuatan Tekan Restorasi Sandwich Berbasis Pressure Strength of Sandwich Restoration Based on Glass Ionomer Cement Fuji II and Fuji IX. J Mater Kedokt Gigi. 2012;2(ISSN 2302- 5271):44-139

[15] Baig MM, Mustafa M, Al Jeaidi ZA, Al- Muhaiza M. Microleakage evaluation in restorations using difference resin composite insertion techniques and liners in preparations with high c-factor - An in vitro study. King Saud Univ J Dent Sci. 2013;4(2):57-64

[16] Sahu S, Ali N, Misuriya A, Vijaywargiya Saha SG, Bharadwaj A. Comparative Evaluation of Microleakage in Class I Cavities Restored with Amalgam, Bulk- fill Composite and Centurion-N - An In Vitro Confocal Laser Scanning Microscope Study. INTERN J Curr Res. 2018;6(1):5-8

[17] Kini A, Shetty S, Bhat R, Shetty P. Microleakage Evaluation of an Alkasite Restorative Material: An In Vitro Dye Penetration Study. J Contemp Dent Pract 2019;(245):1-3

[18] Syafri M, Nugraheni T, Untara TE. Perbedaan kebocoran mikro resin komposit bulkfill vibrasi sonic dan resin komposit nanohibrid pada kavitas kelas I. J Kedokt Gigi. 2014;5(2):68-158

[19] Aviandani MJ, Munadziroh E. Perbedaan kebocoran tepi tumpatan semen ionomer kaca dengan pengadukan secara mekanik elektrik dan manual. Jurnal PDGI. 2012;61(3):81-120

[20] Perdigão J. Current perspectives on dental adhesion : ( 1 ) Dentin adhesion. 2020;56:190-207
[21] Sundari I, Diansari V, Darlianti N. Study of microleakage in dental enamel using nanofillers composite resin restoration with total-etch and self-etch adhesive. J Syiah Kuala Dent Soc. 2020;5(1):8-1 